\title{
Conditions for Implementing the ICF-CY in Education: The Experience in Portugal
}

\author{
Manuela Sanches-Ferreira ${ }^{1 *}$, Mónica Silveira-Maia', Silvia Alves ${ }^{1}$ \\ and Rune J. Simeonsson ${ }^{2}$
}

${ }^{1}$ Department of Special Education and Inclusion, School of Education, Polytechnic Institute of Porto, Porto, Portugal, ${ }^{2}$ University of North Carolina at Chapel Hill, Chapel Hill, NC, United States

Reflecting international trends for implementing inclusive education, Portugal enacted a special education law (Law No. 3/2008) in 2008, defining substantial changes in educational practice. One of the most important changes consisted in determining that eligibility for special education services be based on the functioning profile of students documented with the International Classification of Functioning, Disability and Health, version for children and youth [ICF-CY, WHO (World Health Organization), 2007]. The study described in this manuscript belongs to a broader project and consisted of the administration of a survey to a nationally representative sample of 551 professionals,

OPEN ACCESS

Edited by:

Susana Castro,

University of Roehampton,

United Kingdom

Reviewed by:

Gregor Ross Maxwell,

UiT The Arctic University of Norway,

Norway

Konstantinos M. Ntinas, Ministry of Education, Research and

Religious Affairs, Greece

*Correspondence: Manuela Sanches-Ferreira manuelaferreira@ese.ipp.pt

Specialty section: This article was submitted to Special Educational Needs, a section of the journal

Frontiers in Education

Received: 12 January 2018 Accepted: 08 March 2018 Published: 27 March 2018

Citation:

Sanches-Ferreira M, Silveira-Maia M, Alves S and Simeonsson RJ (2018)

Conditions for Implementing the ICF-CY in Education: The

Experience in Portugal.

Front. Educ. 3:20.

doi: 10.3389/feduc.2018.00020 to examine factors they considered as most influential to the perceived ease in using the ICF-CY, as well as identifying the extent to which the professional groups and the enrollment on training relates to the opinion about the use of the ICF. For sample recruitment, 414 clusters of schools were randomly selected, stratified according to the distribution of schools in the different Regional Directorates of Education in Portugal. The survey consisted of demographic questions and 49 scaled items, assessed on a 4-point Likert scale in which respondents rated: (i) the perceived ease on the ICF-CY usage; (ii) their level of knowledge on conceptual and procedural aspects inherent to the Law implementation, as well as, on regard to performed roles defined; (iii) the extent to which their schools presented conditions for collaboration; and (iv) the importance of contextual variables as valued conditions for using the ICF-CY. Results showed that the establishment of mechanisms for collaboration and interdisciplinarity were central conditions to meet the comprehensiveness and rigor defining an ICF-CY-based assessment. Likewise, consideration of diverse backgrounds and needs of professional groups in terms of knowledge needs to be a central requirement for implementing an ICF-CY informed approach. An important implication for training programs is to have an expanded focus on demonstrations on how the ICF-CY can be used to support the implementation of socio-ecological and inclusive perspectives.

Keywords: International Classification of Functioning Disability and Health, version for children and youth, special education, inclusion, educational policy, students with additional support needs

\section{INTRODUCTION}

Within the field of education, special education is a dynamic element that has undergone structural changes over the past 30 years progressing toward inclusive and effective instruction for students with additional support needs. Education with quality, efficiency, equity, and fairness are key principles guiding policies and practices aligned with international resolutions, such 
as the Salamanca Statement (UNESCO, 1994) and the UN Convention on the Rights of Persons with Disabilities (CRPD, United Nations, 2006). The respect and valorization of diversity defining inclusive education, ensures student access to mainstream schools, by promoting appropriate learning opportunities for successful engagement of all students-including those with disabilities (e.g., EASNIE, 2011a,b; Florian, 2014). This focus on enabling school environments to meet diverse profiles of children's learning and needs has been a critical factor for adopting a context-sensitive perspective to approach additional support needs of students with disabilities. As systematized by the European Agency for Special Needs and Inclusive Education-EASNIE (2011a), the adoption of such a perspective requires readjustments at different system levels: (i) macro-level-including legislation defining the criteria to base decisions on eligibility and educational interventions; (ii) meso-level-including school community and organization; and (iii) micro-level-embracing factors as classroom practices, knowledge sharing and collaborative processes in considering the specificities of the interaction between each student and the environment. Within this perspective, the Portuguese education system formalized a macro-level reform in 2008 by defining in Law, dimensions of special needs assessment and eligibility.

Inclusion has been on the agenda of the Portuguese Ministry of Education since the seventies. Reflecting that agenda and state responsibility, formalization of the Education Act Law No. 46 in 1986 (Public Law 46/1986, 1986), made a significant contribution to ensure access to education by students with disabilities in least restrictive environments, by assigning the organization of special education services within the regular education system. Following that legislation, challenges for educating children with disabilities have moved beyond access to mainstream settings, to include the implementation of effective individualized supports for a successful participation within general education classrooms (Sanches-Ferreira et al., 2017a,b).

Currently, within the "one track approach" of defining policies and practices toward education for all in European countries, Portugal has one of the highest percentages of students with disabilities in mainstream settings of education. According to the Committee on the Rights of Persons with Disabilities' report (CRPD, United Nations, 2016), about 98\% of students with disabilities attended school in mainstream settings in Portugal in 2015. Recent Portuguese legislation (Public Law 3/2008, 2008) reflected this approach, framing special needs' supports within conceptual, organizational and procedural terms, and was conceptually grounded on the need to:

- promote the implementation of a context-sensitive approach to base special needs assessment, eligibility and educational planning, rather than an impairment-based approach with a strict focus on diagnosis and on "within-child" explanations of disability;

- achieve a greater engagement of the whole school community in supporting the participation of students with additional support needs (including the regular education teacher), rather than assigning supports responsibility merely to specialized professionals (i.e., commonly to special education teacher).

The approach in this legislation builds on a central assumption of the social-ecological model conceiving of disability and functioning as processes reflecting the interaction between the person and the environment [WHO (World Health Organization, 2001, 2007); Schalock et al., 2010]. Such a context-sensitive approach has been advanced as a way to improve educational strategies to promote students' participation and learning (e.g., Simeonsson et al., 2008; Norwich, 2008; Hollenweger, 2013). Moreover, the importance of building an inclusive culture has been underlining the construction of support networks involving the whole school community (Booth and Ainscow, 2002; Schalock et al., 2010), and channeling of specialized knowledge and resources toward natural contexts of participation (specifically through the regular teacher). Addressing these goals, three major reforms were introduced by Law No. 3/2008 (Public Law 3/2008, 2008):

(i) use of the International Classification of Functioning, Disability and Health (ICF) as the basis for a context-sensitive approach on special needs assessment and eligibility processes; implementation of socioecological planning in assessment, and profiling student functioning (documenting personal and environmental characteristics of the student) as the basis for eligibility decision-making and planning of educational interventions;

(ii) assignment of the coordination of students' Individualized Education Programs (IEPs) to the regular education teacher-strengthening the involvement and responsibility of school community and, in particular, of regular teachers in the inclusion process of students with additional support needs;

(iii) transformation of traditional special education schools into Resource Centers for Inclusion, reorienting specialized human resources to promote inclusive processes of children with disabilities (including those with severe and profound conditions) within regular schools.

Introduction of the ICF-CY at a macro-level in a top-down manner had pronounced implications in defining a functioningoriented criterion for assessment and eligibility. In contrast to the traditional classification of disability, defined by a onedimensional approach in determining the nature and/or the severity of biological deficits, the multidimensional framework of the ICF-CY classifies disability and functioning as manifestations of the interaction of body functions (BF) and structures (BS), activities and participation (A\&P), and environmental factors $(\mathrm{EF})$. This multidimensional framework is presented in a taxonomy consisting of a list of variables (categories or codes) describing characteristics of an individual's participation (e.g., focusing attention, learning to write, solving-problems, moving around, interacting with others), BF/BS (e.g., psychomotor control, visual perception, abstraction, control of voluntary movements, speech articulation), and surrounding EF (e.g., methods for education, specific equipment to move). Each category is represented by an alphanumeric code (e.g., d160-focusing 
attention; b147-psychomotor control; e130-methods for education), accompanied with a qualifier reporting the magnitude of the problem that may vary from 0 (no problem) to 4 (complete problem). For example, a student presents with a mild problem of focusing attention in classroom tasks (d160.1), related to deficits of psychomotor control (b1470.2) in the context of an excessive length of activities (e130.2). When describing $\mathrm{EF}$, the qualifiers may be assigned as facilitators or as barriers depending on their impact in supporting or obstructing student participation, respectively. This situation specific approach frames a holistic and comprehensive description of student functioning within a socioecological perspective, matching participation-oriented goals for students in environmental terms (Imms et al., 2017).

The value of aligning universal documents (child and human rights declarations and classifications) with policies and services for children with additional support needs (Simeonsson et al., 2006; Brown and Guralnick, 2012; Norwich, 2016; Castro and Palikara, 2017), has taken the form of adopting an ICF-CY informed approach to special needs assessment and eligibility in a number of countries (Tokunaga, 2008; De Polo et al., 2009; Francescutti et al., 2009; Hollenweger, 2011). In this context, it is important to prioritize the procedures and measures in the adoption of the ICF-CY in order to implement a comprehensive, systematized and shared socioecological approach in education to meet the additional support needs of students with disabilities.

Organizationally, the use of the ICF-CY in Law No. 3/2008 was conceived within a set of assessment and intervention procedures to identify and provide the additional support needed by a student with disabilities. Following a referral for assessment, initiated by parents, teachers or other educational professional, the school principal requests the involvement of an interdisciplinary team to assess student's needs. Interdisciplinary teams are typically composed of regular and special education teachers, parents, psychologists, and staff from the Resource Centers for Inclusion (including speech and occupational therapists). The ICF-CY serves as a reference framework to identify functioning and environmental categories of importance and methods of assessment for a holistic and comprehensive view of student performance. Results of the team assessment are analyzed and a profile of functioning is derived within the interactive framework of ICF-CY domains, summarizing the student's A\&P, BF/BS, and EF. That profile will be used for decision-making in reference to the criteria for special education service eligibility: "students with significant limitations in terms of activity and participation in one or more life domains due to permanent functional and structural issues, which result in continued difficulty in terms of communication, learning, mobility, autonomy, interpersonal relationships and social involvement" (Law No. 3/2008). If the functioning profile of the student meets the eligibility criteria, the team proceeds with the design of an IEP, with goals and strategies grounded on assessment findings. Through these steps, the Law formalized eligibility decision-making based on functioning instead of clinical diagnosis, increasing the congruence of assessment, eligibility determination and educational planning for the student.
Implementation of these steps within the conceptual framework of the Law resulted in the following adjustments to school policies and practices:

- recognition of the determinant role of the environment in shaping student performance and a corresponding understanding of the limitations of clinical diagnoses for education purposes;

- application of knowledge and skills in the use of the ICF-CY;

- constitution of interdisciplinary teams and collaborative mechanisms for bridging roles and responsibilities in defining student performance;

- establishment of communication and collaboration networks between education, health and social ministries, and other community entities.

Faced with requirements for implementing DL No. 3/2008, specifically use of the ICF-CY, the Ministry of Education commissioned a 2-year national evaluation, which consisted of three studies with nationally representative samples (Sanches-Ferreira et al., 2010). A first study involved document analysis of student IEP's to identify profiles of student functioning developed on the basis of the ICF-CY. A second study involved focus group methodology to explore perceptions of persons involved in specialized assessment processes about the decree-law implementation. Table 1 summarizes findings from the two studies.

These first two studies demonstrated that educational teams were already able to use the ICF-CY, emphasizing the A\&P component in the functioning profile of students. However, the EF component of the ICF-CY was not implemented broadly as an interrelated approach (documenting the mutual influences of $\mathrm{BF}$ and EF over students' $\mathrm{A} \& \mathrm{P}$ ). Of particular importance was the finding that the dimension of severity was a key factor in differentiating special education status of students relative to aspects of the student's profile. Although teachers recognized difficulties and challenges in applying the ICF-CY, an important finding was their acknowledgment of the value of the ICF-CY-based assessment for a comprehension view of student strengths and needs.

Complementing findings of the two studies, a third study that is described in this manuscript, involved the administration of a survey to a nationally representative sample of 551 professionals, including regular and special education teachers, school principals, psychologists, and therapists. The survey was designed to examine factors professionals considered as most influential to the perceived ease in using the ICF-CY, as well as to identify the extent to which the professional group and enrollment in ICF-CY training relates to the opinion about the use of the ICF-CY. Five questions were posed for this research study:

i. Are there significant differences in perceptions of ease and time required to implement the ICF-CY between professional groups and between who received and did not receive training?

ii. Are there significant differences in level of knowledge and perceptions of clearness implementing the Law between professional groups and between who received and did not receive $\mathrm{ICF}-\mathrm{CY}$ training? 
TABLE 1 | Review of the first two studies about the evaluation of the implementation of the Law No. 3/2008.

\begin{tabular}{ll}
\hline Reference publications & Method \\
\hline Study 1. & 252 processes of students' subject to a referral \\
Sanches-Ferreira et al. & and subsequent ICF-CY-based assessment \\
$(2013,2015)$ & (including those eligible and non-eligible for \\
& special education services). A documental \\
& analysis was conducted over all assessment \\
& information and documents from the special \\
& education referral to assessment and \\
& determination of eligibility
\end{tabular}
Sanches-Ferreira regular and special education teachers, school et al. (2014)

\section{Results synthesis}

The functioning profiles based on the ICF-CY have supported:

(i) the eligibility decision-making-differencing the profiles of eligible from non-eligible in terms of the severity of the problems assigned to body functions and activity and participation;

(ii) the selection of educational responses-differencing the profiles subject to functioning-oriented curriculum from others in terms of how broad are the number of affected categories on body functions and activities and participation;

(iii) a biopsychosocial perspective, with a focus on functioning and students' performance on activities and participation rather than on body impairments

The assessment processes were mainly based informal methods of data collection (e.g., observation and worksheets), rather than on formal ones (e.g., standardized tools or technical reports)

The ICF-CY-based profiles were not fully serving the IEPs design, with the need of expanding the acknowledgment of environmental factors influencing students' performance, as well as, of exploring other participation domains beyond academic activities

The introduction of an ICF-CY brought to schools a greater: (i) clearness on assessment and decision-making processes; (ii) understanding of students' needs; (iii) interdisciplinary communication vessels, with a great involvement of different professionals, as well as, with the use of a common language.

Difficulties were reported on the ICF-CY use, namely on: (i) selecting relevant codes and assigning qualifiers, with great expression on body functions' classification; (ii) using uniform assessment procedures among schools; (ii) establishing necessary partnerships between school and community entities (namely services from health and social ministries)

TABLE 2 | Demographic characteristics of respondents.

\begin{tabular}{|c|c|c|c|c|c|c|c|}
\hline \multirow[t]{2}{*}{ Professional group } & \multirow[t]{2}{*}{$n(\%)$} & \multirow{2}{*}{$\begin{array}{c}\text { Age } \\
\text { M (SD) }\end{array}$} & \multicolumn{2}{|c|}{ Gender } & \multirow{2}{*}{$\begin{array}{c}\begin{array}{c}\text { Years of } \\
\text { practice }\end{array} \\
M(S D)\end{array}$} & \multirow{2}{*}{$\begin{array}{c}\begin{array}{c}\text { Years of practice } \\
\text { on SEN }\end{array} \\
M(\mathrm{SD})\end{array}$} & \multirow{2}{*}{$\begin{array}{c}\begin{array}{c}\text { Training } \\
\text { on ICF }\end{array} \\
n(\%)\end{array}$} \\
\hline & & & Male, $n(\%)$ & Female, $n(\%)$ & & & \\
\hline Regular education teacher & 176 (31.9) & $43.80(7.17)$ & $21(11.93)$ & $155(88.07)$ & $19.34(8.01)$ & $5.88(5.71)$ & $27(15.34)$ \\
\hline Special education teacher & 277 (50.3) & $44.03(7.95)$ & $31(11.19)$ & $246(88.81)$ & $20.09(8.81)$ & $12.39(8.08)$ & $217(78.34)$ \\
\hline Principal & $44(8.0)$ & $48.52(5.38)$ & $16(36.36)$ & 28 (63.64) & $25.57(6.17)$ & $6.67(5.54)$ & $12(27.27)$ \\
\hline Psychologist & $23(4.2)$ & $43.17(8.14)$ & $4(17.39)$ & 19 (82.61) & $16.39(7.93)$ & $8.50(8.41)$ & $12(52.17)$ \\
\hline Therapists & $31(5.6)$ & $28.94(6.51)$ & $1(3.23)$ & $30(96.77)$ & $6.03(5.86)$ & $5.40(5.91)$ & $16(51.61)$ \\
\hline Total & $551(100)$ & $43.43(8.33)$ & $73(13.2)$ & $478(86.8)$ & $19.36(8.96)$ & $11.06(8.09)$ & $284(51.5)$ \\
\hline
\end{tabular}

iii. Are there significant differences in the extent of collaboration among professionals between professional groups and between who received and did not receive ICF-CY training?

iv. To what extent are contextual attributes, such as the constitution of interdisciplinary teams, training and availability of assessment tools, valued by each professional group as conditions for using the ICF-CY?

v. Is the perceived ease in using the ICF-CY significantly related to respondents' characteristics (years of practice, years of practice on SEN), their level of knowledge about the Law and the extent of collaboration among professionals?

\section{MATERIALS AND METHODS}

\section{Participants}

For sample recruitment, education professionals were randomly drawn from 414 clusters of public schools (schools across all different age groups-from pre-school to secondary educationunder common administrative headquarters) and stratified according to the distribution of clusters in the five Regional Directorates of Education in Portugal. In each selected cluster, the principal was requested to invite professionals involved in the special needs assessment to complete the questionnaire. Specifically, 551 professionals responded to the survey, including regular and special education teachers, as nuclear members of the support team (Sanches-Ferreira et al., 2013, 2014, 2015) and other relevant professionals, including the principal, psychologist and speech, occupational and physiotherapists (Table 2).

It is important to note that the proportion of different professionals responding to the questionnaire is closely related to their proportion in the referral and assessment processes as found in the two previous studies-in keeping with their participation in the study on students' processes and the focus group study (Sanches-Ferreira et al., 2013, 2014, 2015).

Training on the ICF-CY was provided in a wide range of settings, from private institutions to public high schools of education or health and consisted of in-presence courses, with a mean duration of $25 \mathrm{~h}$. It should be mentioned that for occupational 
therapists, training on the ICF, in terms of the occupational and participation-oriented models, was aligned with the curricular content of their licensure.

\section{Instrument}

Data were collected with a self-administered questionnaire with items based on statements in the Law (DL-3/2008) regarding conceptual, organizational and procedural guidelines framing special education services, as well as based on findings of the previous document analysis and focus group studies (Sanches-Ferreira et al., 2013, 2014, 2015). The survey consisted of demographic questions (including gender, age, professional role, years of practice and the attendance to ICF-CY training programs) and questions regarding professionals' experience in implementing the Law. The questions took the form of 49 scaled items, on which respondents rated: (i) the perceived ease on the ICF-CY usage; (ii) their level of knowledge on conceptual (including Salamanca Statement, disability and impairment concepts, inclusive school and special education concepts), and procedural terms (including how to conduct the referral, the specialized assessment, the ICF-CY use for assessment and for eligibility), as well as, on regard to performed roles (e.g., of parents, of principals, of regular and special education teachers, and of pedagogical council); (iii) the extent to which their schools presented conditions for collaboration [comprising factors such as human resources, interdisciplinary team composition and their quality; cooperation between members and services within and outside school; and school organization (time/schedule management for meetings)]; and (iv) the importance attributed to contextual variables as valued conditions for using the ICF-CY, namely the availability of training, partnerships, assessment tools and interdisciplinarity for the assessment students' BF and BS, A\&P and EF. With this, respondents were asked to rate the perceived ease, level of knowledge about the Law and importance of contextual variables for the ICF-CY implementation using a scale between 1 and 4 ( 1 -none, 2-low; 3-moderate, and 4-high).

\section{Validity and Reliability}

The final list of items for the survey was selected following a review of a panel of experts composed of three researchers with extensive involvement on ICF-CY focused projects and training programs. Feedback was also obtained from ten teachers with more than 10 years of practice in special education services who were invited to evaluate the questionnaire with regard to relevance and clarity of items. The survey was then administered to the 551 professionals participating in the study. Analytically, a principal components analysis was carried out to identify subscales within the item pools and to exclude items which did not group in conceptually sound subscales. Bartlett test of sphericity $(p<0.05)$ and the Kaiser-Meyer-Olkin measure (recommended value of 0.6 ) were used to confirm the suitability of using factor analysis on each dataset. An oblique, Direct Oblimin rotation of the data was conducted with extraction of factors with Eigenvalues greater than 1.0. Factor loadings of 0.4 or higher defined the criteria for identifying items in each extracted factor. Internal consistency was tested for each unidimensional subscale using the Cronbach's alpha statistic $(>0.7)$. This resulted in the extraction of 10 subscales with alpha coefficients between 0.73 and 0.95 , legitimizing the computation of a total score for each subscale (Table 3).

\section{Procedure}

Data were collected over a 2-month period, starting about 2 years after the implementation of Law No. 3/2008. The questionnaire was made available online through the software Lime Survey. Questionnaires were accompanied by an introductory letter and a consent form. Reminders were also sent out every week to ensure the gathering of responses from all selected clusters. Confidentiality and anonymity were maintained throughout the research process, with no collection of personal data and with the assignment of a code to deidentify data for each participant.

Ethical approval was obtained directly from the commissioning body's committee responsible for granting ethics approvals (Ministry of Education) and responsible for endorsing our researching team to conduct the study. All subjects gave written informed consent in accordance with the Declaration of Helsinki.

\section{Data Analysis}

All analyses were performed using the SPSS Statistics 23 software package. An initial descriptive analysis was made to summarize the data, with mean and SD derived for each subscale score. The effects of having of not having training in using the ICF-CY and the role of professionals (regular education teacher, special education teacher, principal, psychologist, therapist) on their experience in implementing the Law, were examined with a 2 (having training or not in ICF-CY) $\times 5$ (role of professionals) ANOVA, where knowledge about the Law, the perception of ease and time required in using the ICF-CY and the importance of contextual attributes functioned as dependents variables. In order to investigate the significance of differences between group means, follow-up tests were performed consisting of Bonferroni tests for multiple comparisons of means and $t$-tests for independent samples. To analyze relationships among survey variables, Pearson's correlation coefficients were derived. In all analyses significance was set at $p<0.05$.

\section{RESULTS}

\section{Descriptive Statistics}

Descriptive statistics of the study's variables are shown in Table 4. Overall, the mean of easiness in using the ICF-CY was rated between 2 and 3 meaning a low to moderate easiness. Special education teachers are among professionals who considered the use the ICF-CY more difficult, but on the other hand reported having more knowledge about the issues inherent to the Law implementation, such conceptual knowledge, procedures and roles to be performed by each professional. Among the professionals, special education teachers were also less likely to see the conditions needed for collaboration among professionals as present in schools.

On regard to time consumed, in mean each assessment took about $7 \mathrm{~h}$ for the 456 professionals that provided this information. 
TABLE 3 | Questionnaire' items loadings.

\begin{tabular}{ll}
\hline $\mathbf{N}=\mathbf{5 5 1}$ & A \\
Item & \\
\hline Ease in using the ICF & 0.49 \\
1. Of classifying environmental factors & 0.47 \\
2. Of classifying activities and participation & 0.93 \\
3. Of classifying body functions & 0.92 \\
4. Of classifying body structures &
\end{tabular}

\section{Level of conceptual knowledge}

1. Salamanca statement $\quad 0.68$

2. The concept of inclusive school $\quad 0.89$

3. The concept of special education $\quad 0.91$

4. The concepts of impairment and disability

\section{Level of procedural knowledge}
1. Of the referral process
$-0.54$
2. Of the assessment
3. Of the ICF-CY usage in the assessment process
$-0.85$
3. Of the ICF-Cr usage in the assessment process
4. Of the reasons founding the use of the ICF-CY in the eligibility process

5. Of the law

\begin{tabular}{ll}
\hline Level of knowledge on performed roles & 0.73 \\
1. Of the parents & 0.79 \\
2. Of the regular education teachers & 0.71 \\
3. Of the special education teachers & 0.86 \\
4. Of the principal & 0.82 \\
5. Of the pedagogical council &
\end{tabular}

\section{Extent of collaboration}
1. Pluridisciplinary team constitution
2. Professionals' quality
3. Shared knowledge on ICF-CY
4. Emphasis on functionality rather than diagnosis
5. Recognition of environmental role
6. Support from school' direction to special education services
7. Cooperation with community entities
8. Cooperation with training entities
9. School' responses for non-eligible students
10. Parents' involvement on assessment and intervention
1. Regular teacher' involvement on assessment and intervention
12. Time/schedule management for assessment and intervention
13. Cooperation within the school' team

14. Monitoring cooperative-work

15. Integration of special needs support within the school project

\section{Importance of training}
1. To assess environmental factors
0.76
2. To assess activities and participation
3. To assess body functions
0.77
0.88
4. To assess body structures

\section{Importance of partnerships}
1. To assess environmental factors
$-0.76$
2. To assess activities and participation
3. To assess body functions
$-0.77$
$-0.76$
4. To assess body structures
$-0.72$ 
TABLE 3 | Continued

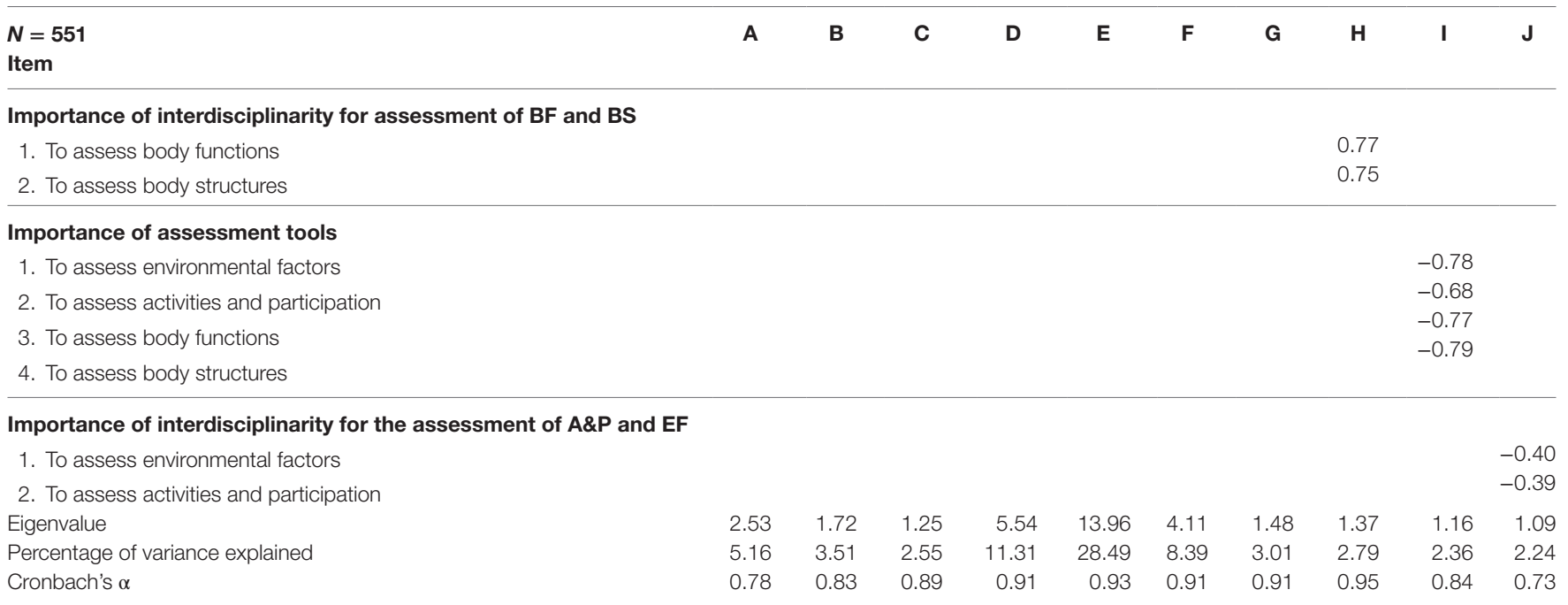

TABLE 4 | Mean and SD of variables considered in this study.

\begin{tabular}{|c|c|c|c|c|c|c|}
\hline & \multicolumn{6}{|c|}{ Professional groups } \\
\hline & $\begin{array}{l}\text { Regular education } \\
\text { teacher }(n=176) \text {, } \\
\text { M (DP) }\end{array}$ & $\begin{array}{c}\text { Special education } \\
\text { teacher } \\
(n=277)\end{array}$ & $\begin{array}{l}\text { Principal } \\
(n=44)\end{array}$ & $\begin{array}{l}\text { Psychologist } \\
(n=23)\end{array}$ & $\begin{array}{l}\text { Therapists } \\
\qquad(n=31)\end{array}$ & $\begin{array}{c}\text { Total } \\
(n=551)\end{array}$ \\
\hline Ease of ICF-CY usage & $2.61(0.56)$ & $2.53(0.56)$ & $2.69(0.48)$ & $2.43(0.50)$ & $2.79(0.63)$ & $2.58(0.56)$ \\
\hline Without ICF-CY training & $2.60(0.58)$ & $2.35(0.59)$ & $2.72(0.51)$ & $2.27(0.41)$ & $2.72(0.54)$ & $2.55(0.58)$ \\
\hline With ICF-CY training & $2.62(0.48)$ & $2.58(0.55)$ & $2.60(0.39)$ & $2.58(0.55)$ & $2.86(0.71)$ & $2.60(0.55)$ \\
\hline Hours consumed in each assessment & $6.00(5.93)$ & $7.32(6.72)$ & $6.25(6.04)$ & $8.22(5.71)$ & $3.22(1.55)$ & $6.74(6.34)$ \\
\hline Without ICF-CY training & $5.87(5.82)$ & $6.34(6.98)$ & $6.69(6.41)$ & $6.43(6.09)$ & $2.56(1.21)$ & $5.97(6.12)$ \\
\hline With ICF-CY training & $6.75(6.47)$ & $7.58(6.64)$ & $5.18(5.15)$ & $9.52(5.33)$ & $3.82(1.63)$ & $7.35(6.45)$ \\
\hline Conceptual knowledge & $2.65(0.53)$ & $3.32(0.43)$ & $3.13(0.55)$ & $3.17(0.47)$ & $2.94(0.49)$ & $3.06(0.57)$ \\
\hline Without ICF-CY training & $2.59(0.53)$ & $3.21(0.39)$ & $3.08(0.59)$ & $3.00(0.37)$ & $3.08(0.59)$ & $2.84(0.58)$ \\
\hline With ICF-CY training & $2.92(0.50)$ & $3.35(0.44)$ & $3.25(0.44)$ & $3.33(0.51)$ & $2.81(0.32)$ & $3.28(0.47)$ \\
\hline Clarity of the law in regard to procedures & $2.38(0.55)$ & $2.82(0.59)$ & $2.74(0.48)$ & $2.64(0.49)$ & $2.61(0.61)$ & $2.65(0.59)$ \\
\hline Without ICF-CY training & $2.36(0.55)$ & $2.64(0.50)$ & $2.74(0.52)$ & $2.45(0.54)$ & $2.77(0.59)$ & $2.50(0.56)$ \\
\hline With ICF-CY training & $2.50(0.52)$ & $2.87(0.59)$ & $2.73(0.37)$ & $2.82(0.38)$ & $2.45(0.61)$ & $2.80(0.59)$ \\
\hline Clarity of the law in regard to performed roles & $2.72(0.63)$ & $3.07(0.59)$ & $3.16(0.58)$ & $2.93(0.48)$ & $2.87(0.71)$ & $2.95(0.63)$ \\
\hline Without ICF-CY training & $2.73(0.64)$ & $2.96(0.54)$ & $3.20(0.60)$ & $2.65(0.39)$ & $2.99(0.73)$ & $2.85(0.63)$ \\
\hline With ICF-CY training & $2.67(0.58)$ & $3.09(0.60)$ & $3.05(0.54)$ & $3.18(0.43)$ & $2.76(0.69)$ & $3.04(0.61)$ \\
\hline Extent of collaboration & $2.85(0.48)$ & $2.75(0.47)$ & $3.06(0.39)$ & $2.78(0.41)$ & $2.70(0.39)$ & $2.80(0.47)$ \\
\hline Without ICF-CY training & $2.86(0.49)$ & $2.73(0.44)$ & $3.09(0.37)$ & $2.68(0.38)$ & $2.79(0.37)$ & $2.85(0.47)$ \\
\hline With ICF-CY training & $2.80(0.44)$ & $2.75(0.48)$ & $2.97(0.42)$ & $2.88(0.42)$ & $2.61(0.39)$ & $2.76(0.47)$ \\
\hline $\begin{array}{l}\text { Importance of contextual variables } \\
\text { for the ICF-CY use training }\end{array}$ & $3.19(0.78)$ & $3.29(0.69)$ & $3.29(0.57)$ & $3.33(0.67)$ & $3.55(0.53)$ & $3.28(0.71)$ \\
\hline Without ICF-CY training & $3.18(0.76)$ & $3.12(0.75)$ & $3.30(0.62)$ & $3.25(0.83)$ & $3.72(0.34)$ & $3.21(0.74)$ \\
\hline With ICF-CY training & $2.28(0.86)$ & $3.34(0.68)$ & $3.27(0.43)$ & $3.40(0.53)$ & $3.39(0.64)$ & $3.33(0.68)$ \\
\hline Partnerships & $3.15(0.75)$ & $3.25(0.68)$ & $3.31(0.58)$ & $3.05(0.69)$ & $3.36(0.57)$ & $3.23(0.69)$ \\
\hline Without ICF-CY training & $3.14(0.75)$ & $3.15(0.66)$ & $3.32(0.62)$ & $3.16(0.87)$ & $3.40(0.52)$ & $3.19(0.71)$ \\
\hline With ICF-CY training & $3.19(0.77)$ & $3.27(0.69)$ & $3.29(0.49)$ & $2.96(0.52)$ & $3.33(0.63)$ & $3.26(0.68)$ \\
\hline Interdisciplinarity in assessment of BF and BS & $3.18(0.77)$ & $3.41(0.74)$ & $3.33(0.66)$ & $3.41(0.63)$ & $3.52(0.72)$ & $3.34(0.75)$ \\
\hline Without ICF-CY training & $3.19(0.77)$ & $3.39(0.70)$ & $3.28(0.72)$ & $3.32(0.72)$ & $3.40(0.74)$ & $3.27(0.74)$ \\
\hline With ICF-CY training & $3.17(0.77)$ & $3.41(0.75)$ & $3.46(0.50)$ & $3.50(0.56)$ & $3.63(0.72)$ & $3.4(0.74)$ \\
\hline Assessment tools & $3.07(0.67)$ & $3.23(0.64)$ & $3.19(0.60)$ & $3.26(0.50)$ & $3.28(0.60)$ & $3.18(0.65)$ \\
\hline Without ICF-CY training & $3.08(0.68)$ & $3.10(0.66)$ & $3.16(0.67)$ & $3.11(0.55)$ & $3.28(0.74)$ & $3.11(0.67)$ \\
\hline With ICF-CY training & $3.02(0.64)$ & $3.27(0.64)$ & $3.29(0.38)$ & $3.40(0.43)$ & $3.28(0.46)$ & $3.25(0.61)$ \\
\hline Interdisciplinarity in assessment of A\&P and EF & $3.28(0.70)$ & $3.47(0.62)$ & $3.35(0.58)$ & $3.59(0.49)$ & $3.74(0.36)$ & $3.42(0.64)$ \\
\hline Without ICF-CY training & $3.29(0.69)$ & $3.43(0.62)$ & $3.28(0.61)$ & $3.50(0.50)$ & $3.70(0.41)$ & $3.35(0.65)$ \\
\hline With ICF-CY training & $3.22(0.76)$ & $3.48(0.63)$ & $3.54(0.45)$ & $3.67(0.49)$ & $3.78(0.31)$ & $3.48(0.62)$ \\
\hline
\end{tabular}

Significance values in statistical terms in bold font. 
However, a deeper analysis showed that $47.8 \%$ of professionals $(n=218)$ spend less than $5 \mathrm{~h}$ in the assessment, $31.1 \%(n=142)$ spend between 5 and $9 \mathrm{~h}, 14.3 \%(n=65)$ spend between 10 and $19 \mathrm{~h}$, and $6.8 \%(n=31)$ spend $\geq 20 \mathrm{~h}$. Furthermore, special education teachers and psychologists are among professionals who spend more time in the student's assessment. Professionals that received training in the $\mathrm{ICF}-\mathrm{CY}$ also tend to spend more time during the assessment.

\section{Easiness and Time Required to Implement ICF-Based Assessment: Professionals' Perceptions and the Influence of Training}

The factorial ANOVA revealed a significant main effect of the professional group on the perceived ease on using the ICF, $F(4,541)=3.43, p=0.01, \eta_{p}^{2}=0.03$. Follow-up pairwise comparisons conducted using Bonferroni correction revealed that the perceived ease in the ICF-CY use was significant lower for both special education teachers $(p=0.02)$ and psychologists than for therapists $(p=0.03)$. Further, no significant main effect for professionals with and without ICF-CY training or an interaction between training and professional group was found on the perceived ease on the ICF-CY usage $[F(1,541)=2.36, p=0.13$, $\eta_{p}^{2}=0.004 ; F(4,541)=1.242, p=0.292, \eta_{p}^{2}=0.009$, respectively $]$. The results showed no significant main effect for professional group or training in ICF-CY or a significant interaction between them on the time spent in each assessment process.

\section{Level of Conceptual Knowledge and of Clearness Recognized on the Law Relative to Procedures and Roles: Professionals' Perceptions and the Influence of Training}

A two-way ANOVA revealed a significant interaction between professional group and ICF-CY training on the level of conceptual knowledge, $F(4,541)=2.41, p=0.004, \eta_{p}^{2}=0.02$. Simple main effects analysis showed that regular and special education teachers $[t(174)=-2.89, p=0.004 ; t(275)=-2.27, p=0.03]$ who received ICF-CY training had significantly more knowledge on the conceptual aspects of the Law than those without the training.

There were significant main effects of professional group and training in the ICF-CY $\left[F(4,541)=19.81, p=0.01, \eta_{p}^{2}=0.13\right.$; $F(1,541)=4.40, p=0.03, \eta_{p}^{2}=0.01$, respectively] on the level of conceptual knowledge professionals considered to have about the Law. Follow-up analysis indicated lower scores for regular education teachers than for others' groups: special education teachers $(p<0.001)$, principals $(p<0.001)$, psychologists $(p<0.001)$, and therapists $(p=0.02)$. Also, there was a significantly lower perceived knowledge by the therapists compared to special education teachers $(p=0.02)$. Overall, professionals with ICF-CY training revealed higher level of conceptual knowledge about the Law.

With respect to the level of clearness assigned to procedural aspects in the Law, the results showed a significant main effect of professional group, $F(4,541)=5.252, p<0.001, \eta_{p}^{2}=0.04$. Follow-up pairwise comparisons indicated lower knowledge for regular education teachers than for special education teachers $(p<0.001)$, and principals $(p=0.002)$. No main effect for having (or not) training in the ICF-CY or an interaction between professional group and ICF-CY training was found on the level of clearness assigned to procedures introduced by the Law.

The results of the $2 \times 5$ ANOVA on the clearness assigned to the Law on regard to the performed roles revealed a significant main effect of professional group, $F(1,541)=5.57, p<0.001$, $\eta_{p}^{2}=0.04$ and no significant main effect for having (or not) ICF-CY training and for the interaction between the professional group and ICF-CY training. Follow-up pairwise comparisons indicated that regular education teacher considered to have less knowledge about the performed roles than special education teachers $(p<0.001)$; and principals $(p<0.001)$.

\section{Presence of Conditions in Schools for Collaboration: Professionals' Perceptions and the Influence of Training}

With respect to the perceived extent of collaboration, a significant main effect was found for the professional group, $F(4,541)=3.30, p=0.01, \eta_{p}^{2}=0.02$ and, following the tendency of last results, no significant main effect for ICF-CY training and for the interaction between the professional group and ICF-CY training. Follow-up analysis revealed that principals reported the presence of higher levels of collaboration than regular education teachers $(p=0.01)$, special education teachers $(p<0.001)$, psychologists $(p=0.02)$, and therapists $(p=0.001)$.

\section{Importance of Contextual Attributes for the ICF-CY Usage: Intra-Group Analysis}

Repeated measures analysis revealed a significant overall difference in the way regular education teachers valued each contextual attribute $F(4,700)=5.02, p=0.001, \eta_{p}^{2}=0.03$. Follow-up pairwise comparisons revealed that the most valued attribute was interdisciplinarity for the assessment of A\&P and EF, scoring higher than assessment tools $(p<0.001)$. Similarly, within the group of special education teachers there were differences in the importance assigned to contextual attributes, $F(4,1,104)=12.82, p<0.001$, $\eta_{p}^{2}=0.04$, with higher scores for interdisciplinarity A\&P and EF assessment than for training $(p<0.001)$, partnerships $(p<0.001)$, and assessment tools $(p<0.001)$. The second most valued attribute was the interdisciplinarity for assessing BF and BS, scoring higher than partnerships and assessment tools $(p=0.003 ; p<0.001)$.

A significantly higher value was also attributed to interdisciplinarity for BF and BS assessment by psychologists on the basis of training $(p=0.01)$. Among therapists, the most valued condition was interdisciplinarity for A\&P and EF' assessment, with higher scores than for partnerships $(p=0.01)$ and assessment tools $(p=0.01)$.

\section{Relation Between the Perceived Ease in Using the ICF-CY and Respondents' Characteristics, Level of Knowledge About the Extent of Collaboration}

Table 5 displays Pearson's correlation coefficient $(r)$ between the perceived ease in using the ICF-CY and other variables under 
TABLE 5 | Pearson's correlation coefficient $(r)$ between the perceived ease in using the ICF-CY and other dependent variables.

\begin{tabular}{|c|c|c|c|c|c|c|c|}
\hline $\begin{array}{l}\text { Perceived ease in } \\
\text { using the ICF-CY }\end{array}$ & $\begin{array}{c}\text { Years of } \\
\text { practice } \\
(r)\end{array}$ & $\begin{array}{l}\text { Years of } \\
\text { practice on } \\
\text { SEN }(r)\end{array}$ & $\begin{array}{l}\text { Time } \\
\text { require } \\
(r)\end{array}$ & $\begin{array}{c}\text { Level of } \\
\text { conceptual } \\
\text { knowledge }(\boldsymbol{r})\end{array}$ & $\begin{array}{c}\text { Level of } \\
\text { procedural } \\
\text { knowledge }(r)\end{array}$ & $\begin{array}{c}\text { Level of } \\
\text { knowledge on } \\
\text { performed roles }(r)\end{array}$ & $\begin{array}{c}\text { Extent of } \\
\text { collaboration }(r)\end{array}$ \\
\hline Total $(n=551)$ & -0.01 & -0.028 & $-0.16^{\star}$ & 0.07 & $0.33^{\star}$ & $0.23^{\star}$ & $0.29^{\star}$ \\
\hline $\begin{array}{l}\text { Regular education } \\
\text { teacher }(n=176)\end{array}$ & -0.08 & -0.16 & $-0.27^{\star}$ & 0.13 & $0.25^{\star}$ & $0.22^{\star}$ & $0.22^{\star}$ \\
\hline $\begin{array}{l}\text { Special education } \\
\text { teacher }(n=277)\end{array}$ & 0.033 & 0.001 & -0.11 & $0.13^{\star}$ & $0.43^{\star}$ & $0.29^{\star}$ & $0.37^{\star}$ \\
\hline
\end{tabular}

teacher $(n=277)$

${ }^{*} p<0.0 .5$.

analysis for the two representative groups of professionals, regular and special education teachers.

Overall, no significant association was found between the years of practice on SEN and the ease perceived in the ICF-CY use. The level of conceptual knowledge was positively correlated with the perceived ease in using the ICF-CY, but only for special education displaying a weak correlation. Significant positive correlations were found between clearness assigned to procedural information in the Law and to performed roles by regular and special education teachers. This means that teachers with higher levels of knowledge about procedures and roles defined by the Law perceived the ICF-CY as easier to use in the student's assessment process. The same result was verified for the extent of collaboration. Teachers reporting more collaborative mechanisms in their schools also considered the ICF-CY easier to use.

\section{DISCUSSION}

In the field of education, political reforms embody a movement in constant motion. A systematic evaluation of the impact of reforms, exploring how they are implemented, how supports facilitate accomplishment, and what are achieved outcomes, is a critical requirement for evidence-based policymaking (Gersten and Dimino, 2006). Within special education field, a wide consensus on the utility of multidimensional models has been reached, as providing comprehensive information on students' performance and enhancing the continuity between assessment and intervention processes (e.g., Simeonsson et al., 2008; Hollenweger, 2013). The ICF-CY use on education-as reflecting a multidimensional perspective over human functioning-has been, then, conceived as an important support for guiding special needs assessment and eligibility processes (e.g., Simeonsson et al., 2006; Brown and Guralnick, 2012; Norwich, 2016; SilveiraMaia et al., 2016; Castro and Palikara, 2017).

This study belongs to a broader research project that was preceded by documental analysis and focus group methods which focused the descriptions of students' functioning profiles and the professionals' perceptions about the Law implementation, respectively. Our third study, the focus of this article, was built, then on findings of the two previous studies concluding that ICFCY-based assessments (i) enabled a deeper and comprehensive view of students' needs and (ii) supported functioning-oriented descriptions of students' profiles emphasizing severity levels of $\mathrm{A} \& \mathrm{P}$ as the basis for decision-making for eligibility.
The present study focused the implementation of the law, and specifically the ICF-CY use, as a process influenced by different contextual conditions. Beyond adoption, implementing reforms or innovations, as the use of the ICF-CY for special needs assessment and eligibility, depends on factors posed at different system levels. Based on the report "Bridging the Know-Do gap" of the WHO (World Health Organization) (2005), Greenhalgh and Wieringa (2011) underline that knowledge translation-like the one that, in this case, was brought by the Law-depends on enabling factors such local knowledge, political support for implementation and strategic presence on local decision-making bodies. Listed barriers included the complexity of the evidence, implementing costs (as being time consuming), and "paradigm differences" between those involved in implementing the innovation.

At a time when different countries around the world have been introducing the ICF-CY as a new approach to special needs assessment and eligibility (e.g., Tokunaga, 2008; De Polo et al., 2009; Francescutti et al., 2009; Hollenweger, 2011; SanchesFerreira et al., 2013, 2017a), there is a priority to identify enabling factors and barriers in bridging the ICF conceptual framework with an educational praxis aligned with a biopsychosocial and an inclusive perspective. In this study, knowledge and contextual attributes have been examined in terms of their perceived impact on enabling the ICF-CY usage in education. Such analysis was conducted exploring possible differences on the way that the ICF-CY use was experienced across professional groups and among those who had or had not been enrolled in ICF-CY training programs. Study findings discussed below, are organized around the five research questions that guided the survey.

\section{Ease and Time Required to Implement ICF-Based Assessment: Professionals' Perceptions and the Influence of Training}

A consensus in the literature is that time, or the lack of it, is one of the critical factors in the implementation of change or innovation [WHO (World Health Organization), 2005; Lia-Hoagberg et al., 1999]. Similarly, in Portugal, time constrictions embodied one of the first concerns of the teachers concerning the Law implementation (Sanches-Ferreira et al., 2014). Considering the assessment process-from planning to the description of the functioning profile-our respondents reported a mean of 3-8 $\mathrm{h}$ spent in each ICF-based assessment. That time estimation 
does not substantially differ from the mean duration indicated in other studies that focused assessment processes in the field of special education (e.g., Lebeer et al., 2013; Schwab et al., 2015). Such findings, seem to exclude the conception of the use of the ICF-CY as requiring additional time for conducing the special needs assessment; and reinforces the linkage between the perception of the lack of time in school management and organization matters frequently documented by professionals (Sanches-Ferreira et al., 2014).

Globally the ease of ICF-CY usage was classified as low to moderate, highlighting the need for training and routinization of the new practices. Based on descriptive statistics, the special education teachers embodied the group that spent more hours per assessment and reported less ease in the use of the ICF-CY. Hours spent and the challenges recognized in assessment seem to underline the leading role performed by special education teachers in the assessment process, as also evident in the two previous studies (Sanches-Ferreira et al., 2013, 2014, 2015). Along with special education teachers, psychologists were the professional group more involved in the assessment process in terms of hours spent, and also registered low scores on ease in the use of the ICF-CY.

Therapists reported higher ease in the ICF-CY usage and registered lower mean times spent in the assessment (a mean of $3 \mathrm{~h}$ ). Although, the greatest perceived ease of ICF-CY use may be explained by the little involvement (in terms of time) in the assessment, the fact of integrating ICF-CY framework in their initial training' curriculums may embody also an explanation. Nevertheless, considering the influence of having any ICF-CY specific training, there were no statistically significant differences between those who had been enrolled in ICF-CY training program compared to those who had not with regard perceived ease in using the ICF-CY.

\section{Level of Knowledge and Perceptions of Clearness Implementing the Law Between Professional Groups and Between Those Who Received and Did Not Receive ICF-CY Training}

Among special education teachers, higher conceptual knowledge (including concepts of impairment, disability, special education, and inclusion) was registered, as well as a greater perception of clarity about information in the Law concerning procedures and performed roles.

Regular education teachers were the less knowledgeable group, not only with reference to ICF-CY concepts but also with regard to the clarity perceived in the procedures and performed roles. This result seems to be in line with the conclusion of the previous two studies (Sanches-Ferreira et al., 2013, 2014, 2015) that revealed a postponed involvement of this professional group on assessment and eligibility processes by the time of the national evaluation. Those results seem to contrast with the growing responsibility ascribed to regular education teachers as coordinators of the IEP implementation (Law No. 3/2008) and raises a discussion about the limited existence of courses related to inclusive education and special education needs in the general education teacher training programs (EASNIE, 2011b). Following regular education teachers, the therapists embodied the professional group less knowledgeable in conceptual terms. Therefore, the same conclusion drawn with regard to regular education teachers' initial training-specifically the lack of courses related to inclusive education-can also be drawn with regard to therapists.

Concerning the influence of ICF-CY training, differences were found on the extent of conceptual knowledge, specifically within regular and special education teachers' groups. No statistically significant impact was registered, however on the factors of clearness of procedural and performed roles. Considering also the low impact of the training programs on the perceived ease in the use of the ICF-CY, these results may suggest that the structure and contents of the training programs are mainly centered on conceptual aspects related to the ICF-CY framework without the same emphasis on translating such conceptions at the procedural level.

\section{Extent of Collaboration and Valued Contextual Attributes for Using the ICF-CY}

The extent of collaboration was globally perceived as moderate; which-and if interpreted together with the significant differences among professional groups of involvement in the assessment (in terms of time) - which seems to underline the need of expanding a collaborative culture within the schools. Actually, interdisciplinarity was the most valued contextual attribute for implementing ICF-based assessments, when compared with other attributes such as training, partnerships, and assessment tools. These findings seem to reinforce the establishment of collaboration mechanisms within educational teams as a critical condition to implement ICF-CY-based assessments.

\section{Relationships Between the Perceived Ease in Using the ICF-CY and Respondents' Characteristics, Level of Knowledge, and Extent of Collaboration}

Our results globally showed that the ICF-CY usage-in terms of its perceived ease-significantly relates with: (i) the clearness perceived on the Law regarding to adopting procedures (including how to conduct the referral, the specialized assessment, the ICF-CY use for assessment and for eligibility) and to the performed roles (i.e., each person-parents, principals, regular and special education teachers, and pedagogical council) contribution and responsibilities; (ii) and with the extent of collaboration implemented within and outside school. The linkage of the ease of use of the ICF-CY with clarity of procedural and performed roles, but not with conceptual knowledge, may reflect a first stage of implementation mainly concerned with a procedural and technical compliance of the Law. A further and deeper appropriation of the ICF-CY framework, matching its conceptual and taxonomic properties with the principles defining inclusion and special needs responses, may embody a second stage that would trigger a greater ease in use of the ICF-CY. The 
relationship found between the extent of collaboration and the ease of using the ICF-CY, seems to reinforce-once again - the use of the ICF-CY as requiring and facilitating the intersection of different perspectives and areas of knowledge (e.g., Hollenweger, 2013; Norwich, 2016).

\section{CONCLUSION}

The findings of this study indicate that the establishment of mechanisms for collaboration and interdisciplinarity were central conditions for meeting the comprehensiveness and rigor defining an ICF-CY-based assessment. Likewise, considering diverse backgrounds and needs of professional groups in terms of knowledge seems also to be a central requirement for implementing an ICF-CY informed approach. Regarding the extent to which receiving ICF-CY training impacts the experience of implementing the Law, our results suggest an influence on the extent of conceptual knowledge, specifically within regular and special education teachers' groups. No statistically significant impact was found, however on the ease perceived in using the ICF-CY, as well as on the factors of clearness of procedural and performed roles, or on the extent of collaboration. Undoubtedly the ICF-CY training plays a critical role in supporting its meaningful usage in education as it was reflected, not only, on our focus group study (Sanches-Ferreira et al., 2014), but also, in the growing number of studies focused on evaluating the impact of ICF-CY in-service training programs (e.g., Reed et al., 2008; Pless et al., 2009; Sanches-Ferreira et al., 2017b). Nevertheless, from the strict impact of the training on conceptual knowledge, recognizing that this factor was not related to the perceived ease of ICF-CY use, several conclusions can

\section{REFERENCES}

Booth, T., and Ainscow, M. (2002). Index for Inclusion: Developing Learning and Participation in Schools. Bristol: Centre for Students on Inclusive Education.

Brown, S. E., and Guralnick, M. J. (2012). International human rights to early intervention for infants and young children with disabilities: tools for global advocacy. Infants Young Child. 25, 270-285. doi:10.1097/IYC.0b013e318268fa49

Castro, S., and Palikara, O. (2017). An Emerging Approach to Education and Care. Implementing a Worldwide Classification of Functioning and Disability. New York: Routledge.

De Polo, G., Pradal, M., Bortolot, S., Buffoni, M., and Martinuzzi, A. (2009). Children with disability at school: the application of ICF-CY in the Veneto region. Disabil. Rehabil. 31, 67-73. doi:10.3109/09638280903317880

Dearing, J. W. (2009). Applying diffusion of innovation theory to intervention development. Res. Soc. Work Pract. 19, 503-518. doi:10.1177/ 1049731509335569

EASNIE. (2011a). Participation in Inclusive Education - A Framework for Developing Indicators. Odense, Denmark: European Agency for Special Needs and Inclusive Education.

EASNIE. (2011b). Teacher Education for Inclusion Across Europe - Challenges and Opportunities. Odense, Denmark: European Agency for Development in Special Needs Education.

Florian, L. (2014). What counts as evidence of inclusive education? Eur. J. Spec. Needs Educ. 29, 286-294. doi:10.1080/08856257.2014.933551

Francescutti, C., Fusaro, G., Leonardi, M., Martinuzzi, A., Sala, M., Russo, E., et al. (2009). Italian ICF training programs: describing and promoting human functioning and research. Disabil. Rehabil. 31(Suppl. 1), S46-S49. doi:10.3109/ 09638280903317757 be drawn about the ICF-CY training programs. Specifically, a conceptual approach integrating concepts of inclusion, special education, disability and impairment, and providing practical demonstrations in using the ICF-CY in a way aligned with key assumptions of socioecological and inclusion perspectives, seem to be critical steps that need to be addressed in training programs. As emphasized by Dearing (2009), communicating and showing why an innovation works, rather than merely talking about what it is, embody key factors for successful implementation. Reflecting this emphasis, the association between the clearness perceived in the Law regarding the procedural information and the ease of using the ICF-CY, expressed by regular and special education teachers, also reinforces the importance of incorporating practical demonstrations on how the ICF-CY framework can be implemented in assessment policy and practice.

\section{ETHICS STATEMENT}

This study was carried out in accordance with requirements of the Portuguese Ministry of Education. The protocol was approved by the commissioning body's committee responsible for granting ethics approvals (Ministry of Education) and responsible for endorsing our researching team to conduct the study. All subjects gave written informed consent in accordance with the Declaration of Helsinki.

\section{AUTHOR CONTRIBUTIONS}

All authors have written, reviewed, and approved the complete manuscript (MS-F, MS-M, SA, and RS).

Gersten, R., and Dimino, J. A. (2006). RTI (response to intervention): rethinking special education for students with reading difficulties (yet again). Read. Res. Q. 41, 99-108. doi:10.1598/RRQ.41.1.5

Greenhalgh, T., and Wieringa, S. (2011). Is it time to drop the "knowledge translation' metaphor? A critical literature review. J. R. Soc. Med. 104, 501-509. doi:10.1258/jrsm.2011.110285

Hollenweger, J. (2011). Development of an ICF-based eligibility procedure for education in Switzerland. BMC Public Health 11:S7. doi:10.1186/1471-2458-11-S4-S7

Hollenweger, J. (2013). Developing applications of the ICF in education systems: addressing issues of knowledge creation, management and transfer. Disabil. Rehabil. 35, 1087-1091. doi:10.3109/09638288.2012.740135

Imms, C., Granlund, M., Wilson, P. H., Steenbergen, B., Rosenbaum, P. L., and Gordon, A. M. (2017). Participation, both a means and an end: a conceptual analysis of processes and outcomes in childhood disability. Dev. Med. Child Neurol. 59, 16-25. doi:10.1111/dmcn.13237

Lebeer, J. O., Partanen, P., Candeias, A., GrÁCio, M. L., Bohacs, K., SØNnesyn, G., et al. (2013). The need for a more dynamic and ecological assessment of children experiencing barriers to learning to move towards inclusive education: a summary of results of the Daffodil project. Transylvanian J. Psychol. Special Issue, 175-205.

Lia-Hoagberg, B., Schaffer, M., and Strohschein, S. (1999). Public health nursing practice guidelines: an evaluation of dissemination and use. Public Health Nurs. 16, 397-404. doi:10.1046/j.1525-1446.1999.00397.x

Norwich, B. (2008). "Perspectives and purposes of disability classification systems: implications for teachers and curriculum," in Disability Classification in Education: Issues and Perspectives, eds L. Florian and M. Mclaughlin (California: Corwin Press), 131-149.

Norwich, B. (2016). Conceptualizing special educational needs using a biopsychosocial model in England: the prospects and challenges of using the international 
classification of functioning framework. Front. Educ. 1, 1-29. doi:10.3389/ feduc.2016.00005

PL 3/2008 - Public Law 3/2008. (2008). Ministry of education. Republic diary. Series no. 4-7 January. 154-164.

PL 46/1986 - Public Law 46/1986. (1986). Ministry of education. Republic diary. Series no. 1 October. 3067-3081.

Pless, M., Ibragimova, N., Adolfsson, M., Bjorck-Akesson, E., and Granlund, M. (2009). Evaluation of in-service training in using the ICF and ICF version for children and youth. J. Rehabil. Med. 41, 451-458. doi:10.2340/16501977-0359

Reed, M., Dilfer, K., Bufka, L., Scherer, M., Kotzé, P., Tshivhase, M., et al. (2008). Three model curricula for teaching clinicians to use the ICF. Disabil. Rehabil. 30, 927-941. doi:10.1080/09638280701800301

Sanches-Ferreira, M., Silveira-Maia, M., and Alves, S. (2014). The use of the international classification of functioning, disability and health, version for children and youth (ICF-CY), in Portuguese special education assessment and eligibility procedures: the professionals' perceptions. Eur. J. Spec. Needs Educ. 29, 327-343. doi:10.1080/08856257.2014.908025

Sanches-Ferreira, M., Silveira-Maia, M., Alves, S., and Simeonsson, R. (2017a). “The use of the ICF-CY for supporting inclusive practices in education: Portuguese and Armenian experiences," in An Emerging Approach for Education and Care: Implementing a World-Wide Classification of Functioning and Disability, eds S. Castro and O. Palikara (London: Routledge), 53-70.

Sanches-Ferreira, M., Lopes-dos-Santos, P., Alves, S., and Silveira-Maia, M. (2017b). The use of the ICF-CY for describing dynamic functioning profiles: outcomes of a teacher training programme applied in Portugal. Int. J. Inclusive Educ. doi:10.1080/13603116.2017.1412507

Sanches-Ferreira, M., Simeonsson, R., Silveira-Maia, M., Alves, S., Pinheiro, S., and Tavares, A. (2010). Projecto da Avaliação Externa da Implementação do Decreto-Lei $n .^{\circ}$ 3/2008: Relatório Final. Lisboa: Direcção-Geral de Inovação e de Desenvolvimento Curricular.

Sanches-Ferreira, M., Simeonsson, R. J., Silveira-Maia, M., and Alves, S. (2015). Evaluating implementation of the international classification of functioning, disability and health in Portugal's special education law. Int. J. Inclusive Educ. 19, 457-468. doi:10.1080/13603116.2014.940067

Sanches-Ferreira, M., Simeonsson, R. J., Silveira-Maia, M., Alves, S., Tavares, A., and Pinheiro, S. (2013). Portugal's special education law: implementing the international classification of functioning, disability and health in policy and practice. Disabil. Rehabil. 35, 868-873. doi:10.3109/09638288.2012.708816

Schalock, R., Borthwick-Duffy, S., Bradley, V., Buntix, W., Coulter, D., Craig, M., et al. (2010). Intellectual Disability: Definition, Classification, and Systems of Supports. Washington, DC: American Association on Intellectual and Developmental Disabilities.

Schwab, S., Hessels, M. G. P., Obendrauf, T., Polanig, M. C., and Wölflingseder, L. (2015). Assessing special educational needs in Austria: description of labeling practices and their evolution from 1996 to 2013. J. Cogn. Educ. Psychol. 14, 329-342. doi:10.1891/1945-8959.14.3.329

Silveira-Maia, M., Lopes-dos-Santos, P., and Sanches-Ferreira, M. (2016). How the use of the international classification of functioning, disability and health for children and youth changed the individualized education programs in Portugal. Int. J. Inclusive Educ. 21, 573-583. doi:10.1080/13603116.2016. 1218950

Simeonsson, R., Bjorck-Akesson, E., and Bairrão, J. (2006). "Rights of children with disabilities," in Encyclopedia of Disability, ed. G. L. Albrecht (Thousand Oaks, CA: SAGE), 257-259.

Simeonsson, R., Simeonsson, N., and Hollenweger, J. (2008). "International classification of functioning, disability and health for children and youth: a common language for special education," in Disability Classification in Education: Issues and Perspectives, eds L. Florian and M. Mclaughlin (California, CA: Corwin Press), 207-217.

Tokunaga, A. (2008). The attempt of the practical application of international classification of functioning, disability, and health (ICF) as a tool for collaboration among various professionals: a perspective on its applicability to "individualized educational support plan". NISE Bull. 9, 1-26.

United Nations. (2006). Convention on the Rights of Persons with Disabilities. New York: United Nations.

United Nations. (2016). Concluding Observations on the Initial Report of Portugal. New York: United Nations.

UNESCO. (1994). The Salamanca Statement and Framework for Action on Special Needs Education. Salamanca, Spain: UNESCO.

WHO (World Health Organization). (2001). International Classification of Functioning, Disability and Health (ICF). Geneva: WHO.

WHO (World Health Organization). (2005). Bridging the "Know-Do" Gap: Meeting on Knowledge Translation in Global Health 10-12 October 2005. Geneva: WHO.

WHO (World Health Organization). (2007). International Classification of Functioning, Disability and Health - Version for Children and Youth (ICF-CY). Geneva: WHO.

Conflict of Interest Statement: The authors declare that the research was conducted in the absence of any commercial or financial relationships that could be construed as a potential conflict of interest.

Copyright (c) 2018 Sanches-Ferreira, Silveira-Maia, Alves and Simeonsson. This is an open-access article distributed under the terms of the Creative Commons Attribution License (CC BY). The use, distribution or reproduction in other forums is permitted, provided the original author(s) and the copyright owner are credited and that the original publication in this journal is cited, in accordance with accepted academic practice. No use, distribution or reproduction is permitted which does not comply with these terms. 